\title{
Etiology of community-acquired pneumonia and diagnostic yields of microbiological methods: a 3-year prospective study in Norway
}

Jan C Holter ${ }^{1,4,7^{*}}$, Fredrik Müller ${ }^{5,7}$, Ola Bjørang ${ }^{2}$, Helvi H Samdal ${ }^{2,9}$, Jon B Marthinsen ${ }^{3,10}$, Pål A Jenum², Thor Ueland ${ }^{4,7,8}$, Stig S Frøland ${ }^{4,6,7}$, Pål Aukrust ${ }^{4,6,7,8}$, Einar Husebye $e^{1,7}$ and Lars Heggelund ${ }^{1,7}$

\begin{abstract}
Background: Despite recent advances in microbiological techniques, the etiology of community-acquired pneumonia (CAP) is still not well described. We applied polymerase chain reaction (PCR) and conventional methods to describe etiology of CAP in hospitalized adults and evaluated their respective diagnostic yields.

Methods: 267 CAP patients were enrolled consecutively over our 3-year prospective study. Conventional methods (i.e., bacterial cultures, urinary antigen assays, serology) were combined with nasopharyngeal (NP) and oropharyngeal (OP) swab samples analyzed by real-time quantitative PCR (qPCR) for Streptococcus pneumoniae, and by real-time PCR for Mycoplasma pneumoniae, Chlamydophila pneumoniae, Bordetella pertussis and 12 types of respiratory viruses.

Results: Etiology was established in 167 (63\%) patients with 69 (26\%) patients having $\geq 1$ copathogen. There were 75 (28\%) pure bacterial and 41 (15\%) pure viral infections, and 51 (19\%) viral-bacterial coinfections, resulting in 126 (47\%) patients with bacterial and 92 (34\%) patients with viral etiology. S. pneumoniae (30\%), influenza (15\%) and rhinovirus (12\%) were most commonly identified, typically with $\geq 1$ copathogen. During winter and spring, viruses were detected more frequently $(45 \%, P=.01)$ and usually in combination with bacteria (39\%). PCR improved diagnostic yield by $8 \%$ in 64 cases with complete sampling (and by 15\% in all patients); 5\% for detection of bacteria; 19\% for viruses ( $P=.04$ ); and $16 \%$ for detection of $\geq 1$ copathogen. Etiology was established in $79 \%$ of 43 antibiotic-naive patients with complete sampling. S. pneumoniae qPCR positive rate was significantly higher for OP swab compared to NP swab $(P<.001)$. Positive rates for serology were significantly higher than for real-time $P C R$ in detecting $B$. pertussis $(P=.001)$ and influenza viruses $(P<.001)$.

Conclusions: Etiology could be established in 4 out of 5 CAP patients with the aid of PCR, particularly in diagnosing viral infections. S. pneumoniae and viruses were most frequently identified, usually with copathogens. Viral-bacterial coinfections were more common than pure infections during winter and spring; a finding we consider important in the proper management of CAP. When swabbing for QPCR detection of S. pneumoniae in adult CAP, OP appeared superior to NP, but this finding needs further confirmation.
\end{abstract}

Trial registration: ClinicalTrials.gov Identifier: NCT01563315.

Keywords: Community-acquired pneumonia, Etiology, Microbiology, Virology, Diagnosis

\footnotetext{
*Correspondence: jancho@mail.uio.no

'Department of Internal Medicine, Vestre Viken Hospital Trust, Drammen,

Norway

${ }^{4}$ Research Institute of Internal Medicine, Oslo University Hospital

Rikshospitalet, Oslo, Norway

Full list of author information is available at the end of the article
}

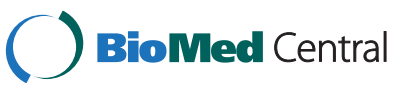

(c) 2015 Holter et al.; licensee BioMed Central. This is an Open Access article distributed under the terms of the Creative Commons Attribution License (http://creativecommons.org/licenses/by/4.0), which permits unrestricted use, distribution, and reproduction in any medium, provided the original work is properly credited. The Creative Commons Public Domain Dedication waiver (http://creativecommons.org/publicdomain/zero/1.0/) applies to the data made available in this article, unless otherwise stated. 


\section{Background}

Community-acquired pneumonia (CAP) is a common disease and a significant cause of morbidity and mortality worldwide [1-3]. Differences in epidemiology of pathogens make the knowledge of local etiology crucial for the appropriate choice of empirical antimicrobial treatment, which has a major impact on the prognosis of the patient [4-7]. An important rationale for microbial testing is to enable pathogen-directed therapy, and thus avoid unnecessary antibiotic use [8]. In clinical practice causative pathogens often remain unknown, and the majority of patients are treated empirically [8]. Moreover, published data on etiology of CAP in Norway [9], as well as in several other countries, are hampered by old data, limited samples and detection methods confined to bacterial culture.

The use of diagnostic methods based on polymerase chain reaction (PCR) have resulted in increased detection of many bacterial and viral pathogens associated with CAP [8]. One of the advantages of PCR is its ability to identify respiratory pathogens also after initiation of antibiotic therapy [10]. Some recent studies have shown that a high microbial yield can be achieved when realtime PCR assays are combined with conventional diagnostic methods like bacterial cultures, urinary antigen assays and serology [11-16]. Such extensive approaches have led to recognition of viruses as important causes of CAP and that coinfections are more common than previously thought $[17,18]$.

The aim of this study was to describe etiology of CAP in adults admitted to a general hospital in South-Eastern Norway using conventional methods and real-time PCR assays for the detection of respiratory pathogens. We also investigated the diagnostic yields of the methods applied, especially the potential benefit of PCR.

\section{Methods}

\section{Patients and study design}

Adults ( $\geq 18$ years old) with suspected pneumonia admitted to Medical Department, Drammen Hospital, Vestre Viken Health Trust-an acute care 270-bed general hospital in the province of South-Eastern Norway serving a mixed rural and urban population of about 160000 inhabitants-were consecutively evaluated for inclusion in a prospective study from January 2008 to January 2011. CAP was defined as (i) presence of a new pulmonary infiltrate on chest radiograph, (ii) rectal temperature $>38.0^{\circ} \mathrm{C}$, and (iii) at least 1 of the following symptoms or signs: cough (productive or nonproductive), dyspnea, respiratory chest pain, crackles or reduced respiratory sounds. These criteria had to be present within $48 \mathrm{~h}$ of admission. Patients were excluded from the study when the chest radiographic examination showed noninfectious causes such as pulmonary infarction, tumor or bronchiectasis, or if the patient was discharged from the hospital within the 2 weeks prior to admission. All study participants were invited to an outpatient follow-up 6 weeks after hospital discharge, including chest radiography and a convalescent blood sample. Consent was obtained at the time of recruitment. The study was approved by the Regional Committee for Medical and Health Research Ethics in South-Eastern Norway (reference number: S-06266a).

\section{Clinical data collection}

Clinical data were recorded on paper case record forms with missing data abstracted from medical records. Chest radiographic patterns were thoroughly examined by an independent experienced radiologist.

\section{Microbial sample collection}

Blood cultures (BD BACTEC ${ }^{\mathrm{mm}}$ Blood Culture System, Sparks, Maryland, USA) were obtained prior to commencing antibiotic therapy. Clinicians at the emergency room or on the wards collected nasopharyngeal (NP) swab samples-and, when possible, sputum specimens for Loeffler stain, Gram stain (optional) and culture-also before initiation of antibiotic therapy. In some cases, these samples were collected at the time of recruitment within $48 \mathrm{~h}$ after hospital admission. An additional NP swab and oropharyngeal (OP) swab from posterior oropharynx and both tonsillar pillars were collected for PCR analysis on separate transport media (Copan Flocked Swabs and UTM-RT Transport Medium System, Brescia, Italy). Urine sample was collected for specific antigen detection. Bronchoalveolar lavage (BAL) and diagnostic thoracentesis were performed on medical indication as judged by the treating clinician, usually when the pneumonia did not resolve, or-in the case of thoracentesis-the cause of build up pleural fluid was not known. Acute-phase serum samples were collected at the time of recruitment. Convalescent-phase serum samples were obtained at the time of outpatient follow-up, approximately 6 weeks after hospital discharge.

\section{Conventional microbiological methods}

Bacteriological specimens were cultured on standard media. BAL was cultured quantitatively in accordance with accepted methods [19]. Growth of specific pathogens detected in sputum and NP samples were judged semiquantitatively as low, intermediate or abundant. The most purulent part of sputum samples was processed for microscopy. Only samples displaying $>25$ polymorphonuclear leukocytes and $<10$ squamous epithelial cells per $100 \times$ power field were considered acceptable for culture [20]. For serology, commercially available assays were used according to the manufacturer's instructions for detection of Mycoplasma pneumoniae, Chlamydophila pneumoniae, Bordetella pertussis, and influenza A and B viruses (see Additional file 1). Urinary antigen detection tests for 
Streptococcus pneumoniae and Legionella pneumophila serogroup 1 were performed with the BinaxNOW pneumococcal urinary antigen test and the BinaxNOW Legionella urinary antigen test (Binax, ME, USA).

\section{PCR}

All NP and OP samples were analyzed by real-time quantitative PCR (qPCR) for detection of $S$. pneumoniae using primers specific for the pneumolysin (ply) gene as described by Greiner et al. [21]; by real-time PCR for presence of bacterial (M. pneumoniae, C. pneumoniae and $B$. pertussis) and adenovirus DNA; and by real-time reverse-transcription PCR (RT-PCR) for detection of RNA viruses (influenza $A$ and $B$ viruses [reported as influenza viruses], and $\mathrm{H} 1 \mathrm{~N} 1$ on influenza A virus positive samples, parainfluenza viruses types 1-3 [reported as parainfluenza viruses], metapneumovirus, rhinovirus, enterovirus and respiratory syncytial virus (A and B) [reported as respiratory syncytial virus]). Detection of $S$. pneumoniae and respiratory viruses were performed retrospectively. Sputum samples and BAL were examined, if medically indicated, by use of real-time PCR detection of L. pneumophila and/or Pneumocystis jirovecii. Additional file 1 provide details of the real-time PCR methods and pneumococcal qPCR assay.

\section{Complete sample collection definition}

A complete sample collection constituted the collection of blood, sputum and NP samples for culture; NP and OP samples analyzed for S. pneumoniae, M. pneumoniae, C. pneumoniae, B. pertussis and 12 types of respiratory viruses by use of PCR; serological testing for M. pneumoniae, C. pneumoniae, B. pertussis, and influenza A and $\mathrm{B}$ viruses; and urine antigen assays for detection of pneumococcal and L. pneumophila antigens.

\section{Classification of etiology}

Etiology was considered to be definite if any of the following criteria were met: a microorganism was cultured from blood or pleural fluid; BAL yielded growth of $>10^{5}$ colony-forming units per milliliter $(\mathrm{cfu} / \mathrm{mL})$ of one $\mathrm{mi}$ crobial species; urinary antigen test for S. pneumoniae or L. pneumophila was positive; or real-time PCR detection of $L$. pneumophila or $P$. jirovecii in sputum samples or BAL was positive.

Etiology was considered to be probable if any of the following criteria were met: bacteria cultured from sputum or NP swabs (at least intermediate growth was demanded for bacteria other than S. pneumoniae where any quantity of growth was accepted); real-time PCR detection of $M$. pneumoniae, C. pneumoniae, B. pertussis or a respiratory virus was positive; serological diagnosis of $M$. pneumoniae, C. pneumoniae or influenza viruses by CFT seroconversion (i.e., $<10$ to $\geq 20$ or conversely), or a 4 -fold titer rise or fall, or a high CFT titer (i.e., M. pneumoniae $\geq 160, C$. pneumoniae $\geq 80$, influenza A virus $\geq 160$, influenza $\mathrm{B}$ virus $\geq 80$ ) of either one or both of acute- and convalescentphase samples, or presence of IgM antibodies $\geq 840 \mathrm{U} / \mathrm{mL}$ for $M$. pneumoniae or $\geq 1.1$ cut-off-index for C. pneumoniae; or serological diagnosis of $B$. pertussis by a 2 -fold rise of PT-IgG (to $>30 \mathrm{IU} / \mathrm{mL}$ in convalescent-phase serum) or fall (from $>30 \mathrm{IU} / \mathrm{mL}$ in acute-phase serum), or presence of PT-IgG $\geq 80 \mathrm{IU} / \mathrm{mL}$ in acute- and/or convalescent-phase samples [22,23]. Pneumococcal DNA from NP samples [24] corresponding to $\geq 10^{5} \mathrm{cfu} / \mathrm{mL}$ [25] by use of qPCR was also considered to be of probable significance. The same conclusions were drawn for OP samples based on the results from Principi et al. [26]. A case was considered coinfected if $>1$ pathogen, classified according to the above-mentioned criteria, was found.

\section{Statistical analysis}

Data were analyzed using PASW statistics software, version 20.0 (IBM SPSS, Chicago, IL). Categorical data were summarized using frequency counts and percentages. Continuous data were presented as mean and standard deviation (SD). The McNemar's test with Yates' continuity correction for paired proportions and the kappa statistics were used to compare the different techniques with respect to the percentage with positive results, and to evaluate the degree of agreement, respectively. Methods were selected for comparison based on level of diagnostic significance according to the classification; i.e., only techniques of which a positive result would give the same level of significance (definite or probable) were compared. In case of zero cells, the value of 0.5 was applied to each cell of the table in order to be able to perform the calculations. Kappa value $<0.20$ is poor, $0.21-0.40$ fair, $0.41-0.60$ moderate, $0.61-0.80$ good, and kappa value $>0.81$ is very good agreement. For other category variables, groups were compared by use of Pearson's chi-square test or Fisher's exact test. In all instances a $P$ of $<.05$ (2-tailed) was considered statistically significant.

\section{Results}

\section{Patients}

Of the 320 screened patients, 267 patients were included in the study (Figure 1). Median age was 66 years (range 19-100 years) (Table 1 ). The average stay in the hospital was 6.8 days (range 1-75 days). Forty-eight (18\%) patients were admitted to intensive care unit. The overall 30-day mortality rate was $3.7 \%$ (i.e., 10 of 267 patients died).

\section{Microbiological etiology of CAP}

A definite or probable etiology was established, by all methods, in 167 (63\%) of 267 patients, 58 (22\%) of whom diagnosis was definite. Bacterial etiology was established in 126 (47\%) of patients; S. pneumoniae was 


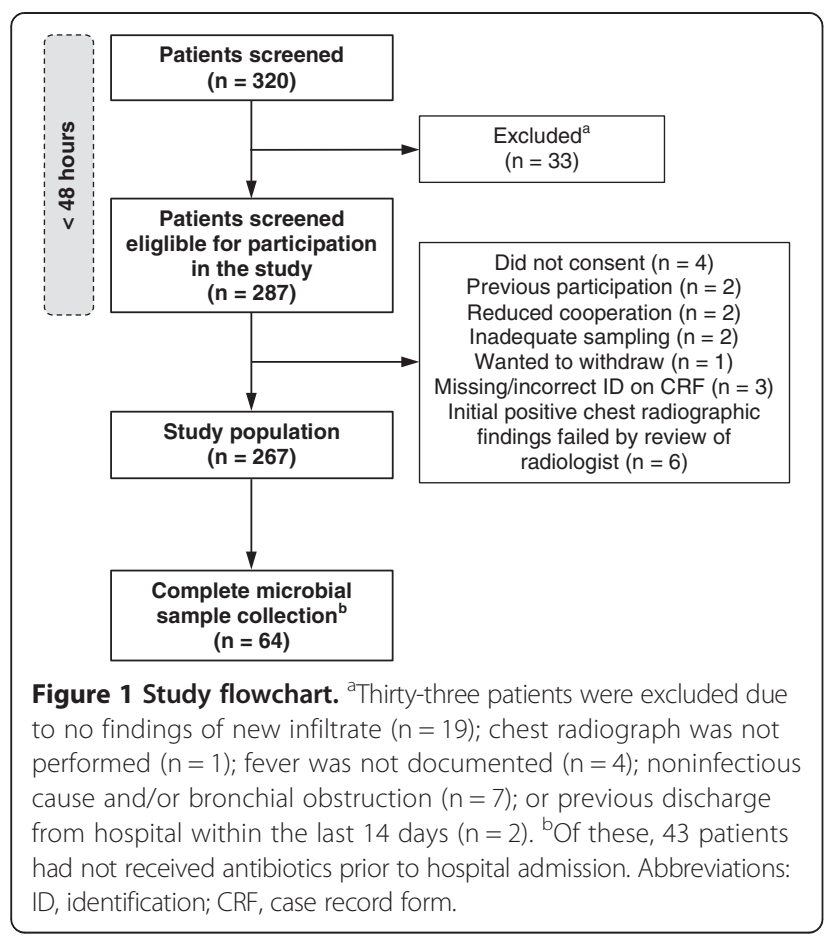

most commonly detected (Table 2). Twenty-five patients (9\%) had bacteremia; 21 (84\%) of these cases had S. pneumoniae isolated of which 2 cases had additional findings of either Haemophilus influenzae or Moraxella catarrhalis. One case had both H. influenzae and Haemophilus parainfluenzae isolated from blood, and Escherichia coli, Pseudomonas aeruginosa and group A streptococci was isolated from one case each. There were 7 cases of legionellosis ( 3 females and 4 males; age range 41-72 years), all caused by $L$. pneumophila serotype 1 . Six of these patients had a documented travel history within past 4 weeks from a Mediterranean country (5 cases) or Asia (1 case), and 1 patient was probably infected while working on a supplyboat in the North Sea. Viral etiology was established in $92(34 \%)$ of 267 patients; influenza viruses were most frequently detected followed by rhinovirus (Table 3). One patient had Pneumocystis jirovecii detected in BAL by use of real-time PCR.

\section{Microbial patterns in CAP patients with an established etiology}

A total of 251 pathogens were detected in the samples from 167 patients, the distribution patterns of the microbial agents identified in these mono- and coinfected patients are presented in Table 4. Multiple pathogens were detected in the samples from 69 (41\%) cases; 1 additional pathogen (copathogen) in 54 (32\%), and 2 copathogens in $15(9 \%)$ cases. S. pneumoniae was identified in 44 (64\%) of the 69 coinfected cases. Also, $\geq 1$ copathogen was detected in 44 (54\%) of 81 episodes with S. pneumoniae.
Table 1 Baseline characteristics of 267 hospitalized adult patients with community-acquired pneumonia

\begin{tabular}{|c|c|}
\hline Characteristics & Patients \\
\hline Age, years & $66(52-78)$ \\
\hline Female/male & $127(48) / 140(52)$ \\
\hline Nursing home resident & $4(1.5)$ \\
\hline Patients with any comorbidity & $172(64)$ \\
\hline Atherosclerosis $^{\mathrm{a}}$ & $71(27)$ \\
\hline COPD & $60(23)$ \\
\hline Immune disorder ${ }^{\mathrm{b}}$ & $34(13)$ \\
\hline Diabetes mellitus & $33(12)$ \\
\hline Renal disease & $32(12)$ \\
\hline Asthma & $25(9)$ \\
\hline Congestive heart failure & $22(8)$ \\
\hline Neurological ${ }^{c}$ & $19(7)$ \\
\hline Dementia & $15(6)$ \\
\hline Active malignancy & $13(5)$ \\
\hline Innate or acquired immunodeficiency ${ }^{d}$ & $11(4)$ \\
\hline Liver disease & $4(1.5)$ \\
\hline Active smoker & $65(24)$ \\
\hline Travel history ${ }^{\mathrm{e}}$ & $37(15)$ \\
\hline Pneumococcal vaccine $e^{f}$ & $25(13)$ \\
\hline Influenza vaccine ${ }^{f}$ & $66(33)$ \\
\hline Antibiotics prior to hospital admission ${ }^{f}$ & $90(36)$ \\
\hline Immunosuppressive drugs ${ }^{g}$ & $37(14)$ \\
\hline
\end{tabular}

Note: Values are presented as No. (\%) or median (25th-75th percentile). COPD, chronic obstructive pulmonary disease.

${ }^{a}$ Coronary heart disease, cerebrovascular disease and/or peripheral artery disease.

${ }^{\mathrm{b}}$ Eleven patients with rheumatoid arthritis, 1 patient with systemic lupus erythematosus, 6 patients with inflammatory bowel disease, 1 patient with autoimmune hepatitis, 3 patients with Sjogren's disease, 14 patients with psoriasis ( 2 patients had 2 conditions).

${ }^{\circ}$ Central nervous disease and/or neuromuscular disease.

dOne patient with antibody deficiency, 1 patient with HIV, 1 patient with heart transplant, 2 patients with kidney transplant, 1 patient with bone marrow transplant. Three patients had received chemotherapy and 2 had received radiation therapy within last 3 months.

${ }^{\mathrm{e}}$ Travel abroad past 4 weeks.

fVaccinated against pneumococcus within previous 10 years; vaccinated against influenza virus within previous 12 months; antibiotics within previous 3 months.

9Immunosuppressive drugs were defined as any use of systemic steroids, Azathioprine, TNF-alpha inhibitor, Cyclosporine, Cyclophosphamide and/or Methotrexate within previous 3 months.

This copathogen was due to 1 additional bacterial agent in 15 (19\%) of cases; and/or $\geq 1$ viral agent in $36(44 \%)$. Accordingly, 36 (82\%) of the 44 coinfected S. pneumoniae episodes were attributed to $\geq 1$ viral agent. A pure bacterial etiology was established in 75 (45\%) of the 167 patients; and a pure viral etiology in 41 (25\%). Viral-bacterial coinfections were established in 51 (31\%) of patients; the most common combinations were $S$. pneumoniae with influenza viruses (16 of 51 patients, 31\%) or rhinovirus (14 of 51, 27\%) (Additional file 1: Table S1). 
Table 2 Bacterial findings and contribution of different methods to diagnostic yield in the study population

\begin{tabular}{|c|c|c|c|c|c|c|c|c|c|c|}
\hline \multirow[t]{2}{*}{ Pathogen } & \multirow{2}{*}{$\begin{array}{l}\text { No. }(\%) \text { of patients } \\
\text { with positive } \\
\text { findings }(n=267)\end{array}$} & \multirow{2}{*}{$\begin{array}{l}\text { Blood culture } \\
(n=267)\end{array}$} & \multirow{2}{*}{$\begin{array}{l}\text { Pleural fluid } \\
\text { culture }(n=14)\end{array}$} & \multirow{2}{*}{$\begin{array}{l}\text { Urinary antigen } \\
\text { test }(n=262)\end{array}$} & \multirow{2}{*}{$\begin{array}{l}\text { BAL } \\
(n=8)\end{array}$} & \multirow{2}{*}{$\begin{array}{l}\text { Sputum sample } \\
\text { for culture and/or } \\
\text { L. pneumophila } \\
\text { PCR }(n=165)^{\mathrm{a}}\end{array}$} & \multirow{2}{*}{$\begin{array}{l}\text { NP swab } \\
\text { culture } \\
(n=263)\end{array}$} & \multicolumn{2}{|l|}{ PCR } & \multirow{2}{*}{$\begin{array}{l}\text { Serology } \\
(n=263)\end{array}$} \\
\hline & & & & & & & & $\begin{array}{l}\text { NP swab } \\
(n=262)^{b}\end{array}$ & $\begin{array}{l}\text { OP swab } \\
(n=262)^{c}\end{array}$ & \\
\hline Streptococcus pneumoniae & $81(30)$ & 21 & - & 24 & - & 4 & 10 & 6 & 16 & NA \\
\hline Bordetella pertussis & $15(6)$ & NA & NA & NA & NA & NA & NA & - & - & 15 \\
\hline Haemophilus influenzae & $14(5)$ & 1 & - & NA & - & 5 & 8 & NA & NA & NA \\
\hline Mycoplasma pneumoniae & $10(4)$ & NA & NA & NA & NA & NA & NA & 7 & 1 & 2 \\
\hline Chlamydophila pneumoniae & 7 (3) & NA & NA & NA & NA & NA & NA & - & 2 & 5 \\
\hline Legionella pneumophila & $7(3)$ & NA & NA & 7 & NA & - & NA & NA & NA & NA \\
\hline Enterobacteriaceae $^{d}$ & $6(2)$ & 2 & - & NA & - & 3 & 1 & NA & NA & NA \\
\hline Moraxella catarrhalis & $5(2)$ & - & - & NA & - & 2 & 3 & NA & NA & NA \\
\hline Miscellaneous ${ }^{e}$ & $3(1)$ & 1 & 1 & NA & - & - & 1 & NA & NA & NA \\
\hline Haemophilus parainfluenzae & $2(1)$ & 1 & - & NA & - & 1 & - & NA & NA & NA \\
\hline Total $^{f}$ & $126(47)$ & 26 & 1 & 31 & - & 15 & 23 & 13 & 19 & 22 \\
\hline
\end{tabular}

Note: Data are number of patients, unless otherwise stated, whose infections were etiologically established by use of a particular method listed in descending order of specificity (NP vs. OP swab PCR depends on

pathogen tested). Additional patients had etiology established by use of different methods; e.g., S. pneumoniae infection was established by use of urinary antigen test in 24 additional patients whose etiology was not established by use of blood culture etc. PCR: S. pneumoniae was detected by use of GPCR; and L. pneumophila, M. pneumoniae, C. pneumoniae and B. pertussis by use of real-time PCR. BAL, bronchoalveolar lavage; qPCR, real-time quantitative polymerase chain reaction; NP, nasopharynx; $\mathrm{OP}$, oropharynx; NA, not applicable.

${ }^{\mathrm{a}}$ Of 165 sputum samples, 73 were of good quality. One of these tested positive for L. pneumophila by use of real-time PCR (urinary antigen test in this case was also positive).

${ }^{b} \mathrm{Of} 262$ patient samples, 240 revealed valid results for qPCR detection of S. pneumoniae, and 259 for real-time PCR detection of M. pneumoniae, C. pneumoniae and B. pertussis.

'Of 262 patient samples, 238 revealed valid results for qPCR detection of S. pneumoniae, and 259 for real-time PCR detection of M. pneumoniae, C. pneumoniae and B. pertussis.

IInclude either of the following: E. coli, P. aeruginosa or Enterobacter species.

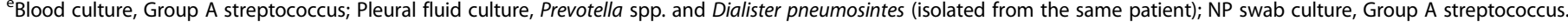

No. of patients does not add up to no. of pathogens because some patients had multiple pathogens detected: a total of 150 bacteria were detected in 126 patients. 
Table 3 Viral findings and contribution of different methods to diagnostic yield in the study population

\begin{tabular}{|c|c|c|c|c|}
\hline \multirow[t]{2}{*}{ Pathogen } & \multirow{2}{*}{$\begin{array}{l}\text { No. }(\%) \text { of patients } \\
\text { with positive } \\
\text { findings }(n=267)\end{array}$} & \multicolumn{2}{|l|}{ Real-time PCR } & \multirow{2}{*}{$\begin{array}{l}\text { Serology } \\
(n=263)\end{array}$} \\
\hline & & NP swab $(n=262)^{a}$ & OP swab $(n=262)^{b}$ & \\
\hline Influenza viruses $^{c}$ & $40(15)$ & 15 & 3 & 22 \\
\hline Rhinovirus & $32(12)$ & 27 & 5 & NA \\
\hline Parainfluenza viruses ${ }^{d}$ & $8(3)$ & 5 & 3 & NA \\
\hline Respiratory syncytial virus ${ }^{\mathrm{e}}$ & $7(3)$ & 7 & - & NA \\
\hline Metapneumovirus & $7(3)$ & 4 & 3 & NA \\
\hline Enterovirus & $5(2)$ & 5 & - & NA \\
\hline Adenovirus & $1(0.4)$ & 1 & - & NA \\
\hline Total $^{f}$ & $92(34)$ & 64 & 14 & 22 \\
\hline
\end{tabular}

Note: Data are number of patients, unless otherwise stated, whose infections were etiologically established by use of a particular method listed in descending order of specificity (NP vs. OP swab PCR are generally considered equally). Additional patients had etiology established by use of different methods; e.g., infection with influenza viruses was established by use of OP swab in 3 additional patients whose etiology was not established by NP swab etc. PCR, polymerase chain reaction; NP, nasopharynx; OP, oropharynx; NA, not applicable.

${ }^{a}$ Of 262 patient samples, 240 revealed valid results for detection of all viruses (except from influenza viruses of which 239 samples revealed valid results).

${ }^{b}$ Of 262 patient samples, 238 revealed valid results for detection of all viruses.

Influenza A virus (13 cases of which 2 cases were H1N1 positive), Influenza B virus (5 cases). 1 case tested positive for both influenza A and B viruses by use of serology.

dParainfluenza virus type 1 (1 case), type 2 ( 2 cases), type 3 (5 cases).

e Respiratory syncytial virus $\mathrm{A}$ (5 cases), 2 cases were undefined.

${ }^{\mathrm{f}} \mathrm{No}$. of patients does not add up to no. of pathogens because some patients had multiple pathogens detected: a total of 100 viruses were detected in 92 patients.

\section{Microbial yield of different diagnostic methods}

Etiology was established by conventional methods (i.e., bacterial cultures, urinary antigen assays and serology) in 127 (48\%) of 267 cases; $\geq 1$ bacterial agent was found in 107 (40\%); and influenza viruses in 37 (14\%). At least 1 copathogen was detected in 29 (11\%) of cases. PCR alone provided etiology in 102 (38\%) of cases; $\geq 1$ bacterial agent was found in 51 (19\%); $\geq 1$ viral agent in $72(27 \%)$; and $\geq 1$ copathogen in 27 (10\%). The total diagnostic yield improved by $15 \%$ ( 167 vs. 127 of cases) when PCR was added to conventional methods. Eleven different types of viruses were detected by PCR.

The diagnostic yields obtained by the diverse methods are shown (Figure 2A and B). The corresponding contribution of each method for establishing bacterial or viral etiology in the study population is illustrated in Table 3 and Table 4, respectively. A pairwise comparison of the diagnostic yield obtained by each technique revealed interesting findings (Additional file 1: Table S2). First, OP swabs revealed significantly more positive results $(34 / 235$ positive, $14.5 \%)$ than NP swabs $(14 / 235,6.0 \%)$ for detection of $S$. pneumoniae by qPCR, $P<.001$. Secondly, for detection of $B$. pertussis serology exhibited significantly more positive results $(13 / 256,5.1 \%)$ than real-time PCR, in both NP and OP swabs (both $0 / 256,0.0 \%$ ) $P=.001$. Similar results were recorded for detection of influenza viruses by serology $(34 / 236,14.4 \%)$ compared to real-time PCR in NP swabs $(15 / 236,6.4 \%) P<.001$; and serology $(34 / 235,14.5 \%)$ compared to real-time PCR in OP swabs (15/235, 6.4\%) $P<.001$. Thirdly, there was no significant difference between sputum culture and NP swab culture for detection of bacteria (Figure 2A). Of note, sputum samples were collected from 165 (62\%) patients; of these were only 73 (44\%) deemed valid for culture by microscopy.

\section{Microbial yield in patients with complete sample collection}

Microbial etiology was established in 47 (73\%) of 64 patients with complete sample collection (Figure 3 ). The total diagnostic yield improved by $8 \%$ (47 vs. 42 of 64 cases, $P=.44)$ when PCR was added to conventional methods; $5 \%$ (37 vs. 34 ) in cases with bacterial etiology; and $19 \%$ (26 vs. $14, P=.04$ ) in cases with viral etiology. Cases with detection of $\geq 1$ copathogen improved by $16 \%$ (22 vs. 12 ). Of 20 (31\%) patients in whom S. pneumoniae was identified, 12 (60\%) had $\geq 1$ copathogen detected. This copathogen was due to $\geq 1$ viral agent in 9 (45\%) of patients. Etiology was established in 34 (79\%) of 43 patients with complete sampling and who had not been prescribed antibiotics prior to hospital admission (not shown).

\section{Seasonality}

Adult CAP patients with viral findings showed marked seasonal variations during the study period; the proportion of cases with positive findings was significantly higher in the winter and spring compared to summer and fall (45\% vs. $28 \%, P=.01$ ) (Figure $4 \mathrm{~A}$ ). Annually outbreaks of influenza viruses and S. pneumoniae contributed to the increase of these findings during the cold half of the year (Additional file 1: Figure S1). Only 2 cases of influenza A (H1N1) virus infection were detected, although the H1N1 pandemic reached our region in the middle of the inclusion period, May 2009. Detection rates of viral-bacterial coinfections in patients with CAP also varied considerably 
Table 4 Distribution of single and multiple bacterial and viral agents detected in 167 adults with an etiologically established diagnosis of community-acquired pneumonia

\begin{tabular}{|c|c|c|c|c|c|}
\hline \multicolumn{6}{|l|}{ Bacterial agents } \\
\hline & \multicolumn{2}{|c|}{ Pure bacterial infections $(n=75)$} & \multicolumn{2}{|c|}{ Viral-bacterial coinfections $(n=51)$} & \multirow{2}{*}{$\begin{array}{l}\text { Total } \\
\text { N (\%) }\end{array}$} \\
\hline & Only one & Plus other bacterium & Plus virus $^{a}$ & Plus virus and other bacterium & \\
\hline Streptococcus pneumoniae & 37 & 8 & 29 & 7 & $81(49)$ \\
\hline Bordetella pertussis & 2 & 4 & 4 & 5 & $15(9)$ \\
\hline Haemophilus influenzae & 2 & 5 & 5 & 2 & $14(8)$ \\
\hline Mycoplasma pneumoniae & 7 & 3 & & & $10(6)$ \\
\hline Chlamydophila pneumoniae & 5 & 1 & & 1 & $7(4)$ \\
\hline Legionella pneumophila & 2 & 3 & & 2 & $7(4)$ \\
\hline Enterobacteriaceae & 1 & 3 & 2 & & $6(4)$ \\
\hline Moraxella catarrhalis & 2 & & 1 & 2 & $5(3)$ \\
\hline Miscellaneous $^{b}$ & 1 & 1 & & 1 & $3(2)$ \\
\hline Haemophilus parainfluenzae & 1 & 1 & & & $2(1)$ \\
\hline Subtotal cases with bacteria & 60 & & & & $126(75)^{c}$ \\
\hline \multicolumn{6}{|l|}{ Viral agents } \\
\hline & \multicolumn{2}{|c|}{ Pure viral infections $(n=41)$} & \multicolumn{2}{|c|}{ Viral-bacterial coinfections $(n=51)$} & Total \\
\hline & Only one & Plus other virus & Plus bacterium $^{a}$ & Plus bacterium and other virus & $\mathrm{N}(\%)$ \\
\hline Influenza viruses & $15^{d}$ & 2 & 21 & 2 & $40(24)$ \\
\hline Rhinovirus & 12 & 2 & 15 & 3 & $32(19)$ \\
\hline Parainfluenza viruses & 3 & & 4 & 1 & $8(5)$ \\
\hline Respiratory syncytial virus & 3 & 2 & 2 & & $7(4)$ \\
\hline Metapneumovirus & 3 & & 3 & 1 & $7(4)$ \\
\hline Enterovirus & 2 & & 1 & 2 & $5(3)$ \\
\hline Adenovirus & & & & 1 & $1(0.6)$ \\
\hline Subtotal cases with viruses & 39 & & & & $92(55)^{c}$ \\
\hline
\end{tabular}

Note: Drammen, Norway, January 2008-January 2011.

ane or two.

${ }^{\mathrm{b}}$ Group A streptococcus; Prevotella spp.; Dialister pneumosintes.

'Patients with multiple agents detected were counted as one individual case.

${ }^{\mathrm{d} O n e}$ patient was also coinfected with Pneumocystis jirovecii.

\section{A}

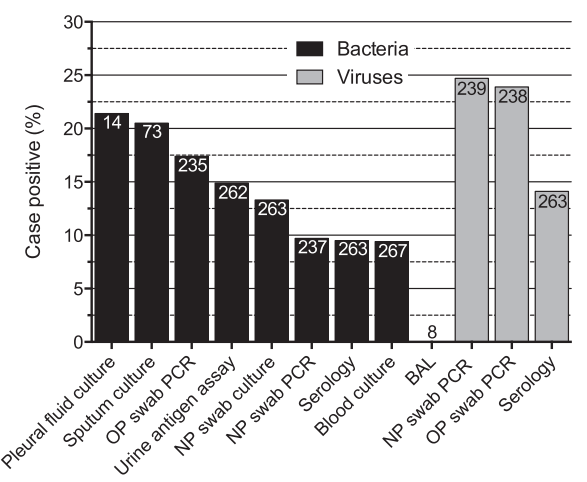

B

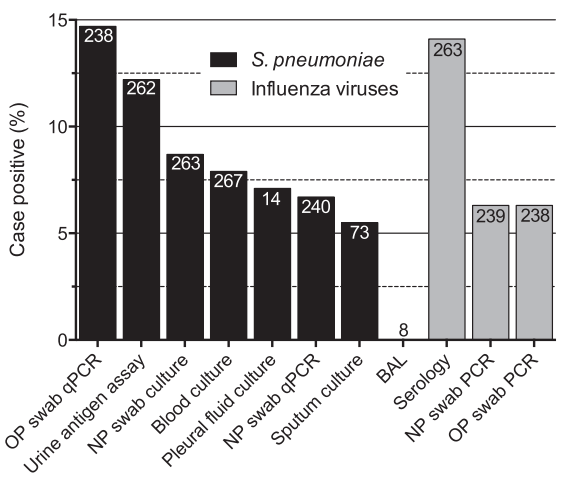

Figure 2 Diagnostic yields of different microbiological methods. Bars are percentages of cases with a positive test relative to the number of cases with a valid test, $n$ (numbers inside the bars). Sputum culture: good-quality sputum by microscopy. A: Detection of bacteria and viruses, regardless of detection spectrum. B: Detection of S. pneumoniae and influenza viruses. OP, oropharynx; NP, nasopharynx; S. pneumoniae, Streptococcus pneumoniae; BAL, bronchoalveolar lavage; $\mathrm{PCR}$, polymerase chain reaction. 


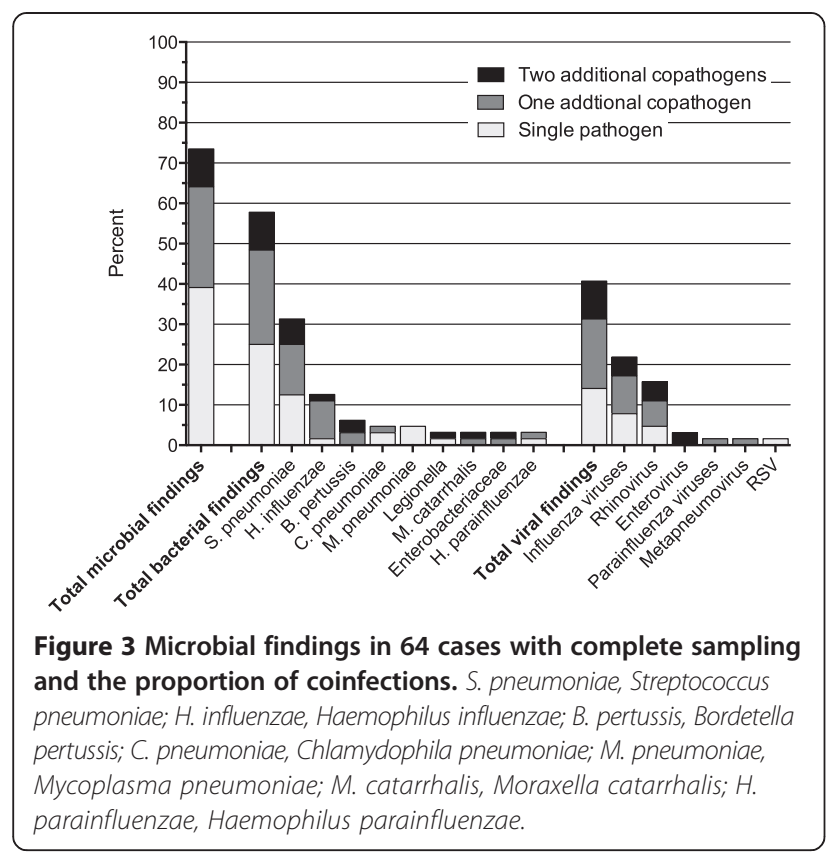

from month to month (range 0\%-60\%), with peaks in January and February (not shown); the proportion of viral-bacterial coinfections was significantly higher in the winter and spring compared to summer and fall (39\% vs. $10 \%, P=.01$ ) (Figure 4B). During winter and spring, viralbacterial coinfections were more frequently detected than either pure infection alone.

\section{Discussion}

This study is the first to describe etiology of CAP in hospitalized adults in Norway using conventional methods and PCR. The main results were: Firstly, etiology was established in the majority of patients, especially when samples were complete and no antibiotics were prescribed prior to hospital admission. Furthermore, PCR improved diagnostic yield, particularly in diagnosing viral infections. Secondly, S. pneumoniae and respiratory viruses (mainly influenza viruses and rhinovirus) were most commonly detected, usually with copathogens. Viruses were detected more frequently during winter and spring, which was also the time period they occurred most commonly in combination with bacteria. Thirdly, OP swabs gave more positive results than NP swabs for qPCR detection of $S$. pneumoniae; and serology gave more positive results than real-time PCR for detection of B. pertussis and influenza viruses.

Establishing a microbiological diagnosis for patients with CAP is challenging. As is the case in any study of samples not obtained through invasive techniques and with quantitation, the link between presence and causal is still quite unclear. However, in this study we applied a vast array of available tests to determine the presence of known pathogens, including those only identified by real-time PCR, following recommendations for interpretation applicable to our region. The diagnostic yield of $63 \%$ is consistent with results of other studies, although reports vary considerably from $39 \%$ to $76 \%$ [11-16,27-31]. These variations may be attributable to differences in the epidemiology of pathogens, study population, diagnostic methods and available patient specimens. The high diagnostic yield that was achieved in the complete sampling group underscores that etiology, nowadays, can be established in the majority of CAP patients if multiple techniques are applied and sample collection is optimized.

The prevalence of S. pneumoniae, other "typical" bacteria and Legionella pneumophila, which almost exclusively occurred in "imported" cases, are in line with previous studies from Northern-Europe $[7,11]$ and USA [32]. $C$. pneumoniae was expectedly uncommon $[7,11]$. The relatively high frequency of $B$. pertussis is probably explained
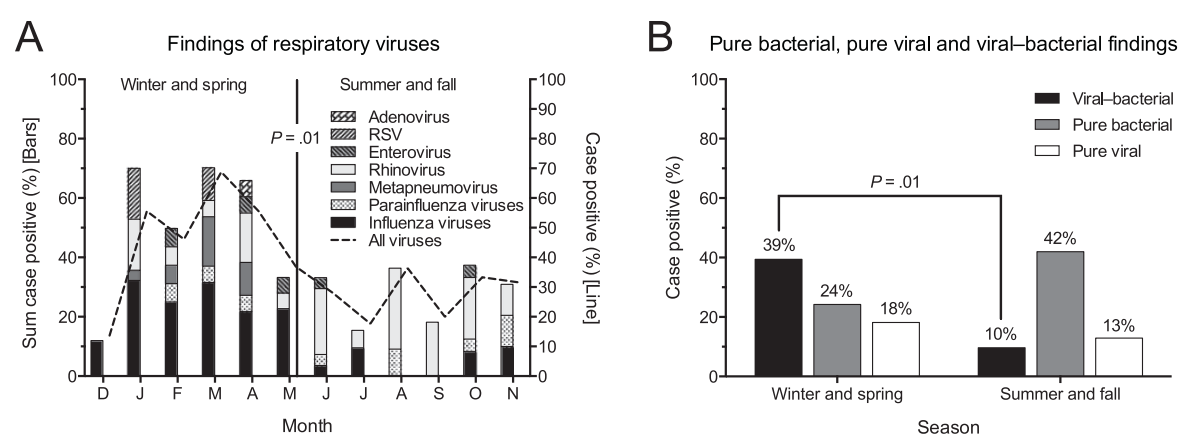

Figure 4 Seasonal variations of microbial findings in patients with CAP during a 3-year period. A: Monthly distribution of viral findings. Each segment in the stacked bars represents the proportion of cases with a positive test relative to those with a valid test for detection of a specific virus. At least one test (PCR or serology) was demanded for a valid detection of influenza viruses $(n=266)$, whereas only PCR for all other viruses $(n=243)$. Continuous line shows the proportion of cases with a positive test of any virus relative to those with a valid test for the complete detection of viruses $(n=231)$. B: Pure bacterial, pure viral and viral-bacterial findings in a subset of 64 patients with complete samples collected. RSV, Respiratory syncytial virus; CAP, community-acquired pneumonia. 
by an ongoing epidemic [33], and the low frequency of $M$. pneumoniae due to timing; the study was conducted between two 5-7 years epidemic cycles [34].

The potential role of viruses in causing pneumonia, both as the sole pathogen as well as in association with bacteria, is debated. Furthermore, the validity of upperairway samples to establish an etiologic diagnosis is controversial. However, the impacts of viruses per se on adult CAP are increasingly being recognized [35-38]. In line with other studies $[11,28,29]$, we identified viruses by all methods in $34 \%$ of all cases and in $41 \%$ of cases with complete sampling. In contrast, conventional methods identified only $14 \%$ of all cases, which confirms the increased sensitivity of PCR reported by others [11,16,39]. As expected, the occurrence of adult CAP with viral findings varied considerably during the year, peaking in March at $\sim 70 \%$, and was significantly higher during winter and spring compared to summer and fall. Influenza viruses were most frequently detected; $14 \%$ by serology compared to $6 \%$ by PCR, the difference between the two methods being statistically significant-and no more than 2 cases of influenza A (H1N1) virus infection were detected by PCR-illustrating the substantial value of serology in epidemiological studies. However, serology is generally not recommended for clinical decision making due to low specificity, which in our study may have led to an overestimation of numbers since a probable diagnosis was not only based on seroconversion but for some patients on high titer in single sample. Interestingly there was no increase in CAP admissions due to influenza viruses during the $2009 \mathrm{H} 1 \mathrm{~N} 1$ pandemic, indicating that influenza viruses are major pathogens regularly occurring in patients hospitalized with CAP irrespective of the H1N1 pandemic. The low diagnostic yield of influenza viruses by PCR technique also underscores the clinical problem with false negative PCR influenza tests, and may suggest that sampling from both the upper and lower respiratory tract should be performed, at least in severely affected individuals [40]. Another explanation may be that the PCR influenza test is more likely to be negative later in the course of a secondary pneumonia to influenza virus infection leading to hospitalization.

Coinfections have previously been reported to account for $4 \%$ to $30 \%$ of adult CAP $[28,30]$. In our study, more than one pathogen was found in $26 \%$ of all patients and in $34 \%$ of patients with complete sampling. In agreement with recent studies, S. pneumoniae was the most common bacterial agent associated with coinfections, and a copathogen was found in more than one-half of the cases with the majority of pathogens being viral agents $[11,12,14,41]$, usually influenza viruses or rhinovirus. One of our important observations, applying comprehensive and complete diagnostics, was an exceptionally high detection rate of viralbacterial coinfections in the course of the winter season, peaking at $60 \%$ in January and February. This number is considerably higher than the $39 \%$ recently reported [40], indicating that seasonal activity patterns of respiratory pathogens also impacts on the occurrence of adult CAP with viral-bacterial coinfections, which appear to be the dominant cause of pneumonia during those times.

Good-quality sputum culture is often difficult to obtain and reported yields are varying [1]. In our study, sputum samples were obtained from $62 \%$ of patients; of those obtained were $56 \%$ judged as inadequate for culture, and of those cultured revealed $21 \%$ a positive result. NP swab cultures were obtained from $99 \%$ of patients; only $13 \%$ of these revealed a positive result. Our concordance analyses indicate, however, that the two methods are complementary.

PCR improved the yield by $8-15 \%$ when combined with conventional methods, proving that PCR is a valuable tool in addition to conventional methods. However, since serological tests have little clinical impact in the acute situation, our findings underscore the need for further improvements. Our results, using flocked swabs, indicate quite equal effectiveness of NP and OP sampling for real-time PCR detection of viruses and the concordance rate between the two specimens was good ( $~ 90 \%)$. These results are in contrast to those from two previous reports $[29,42]$ that observed superiority of NP sampling, one of the studies using flocked swabs [42]. To our knowledge, no study comparing NP and OP sampling for qPCR detection of $S$. pneumoniae in adult CAP has yet been published: In line with the findings of Principi et al. [26], we found that OP swabs were significantly more effective than NP swabs for qPCR detection of S. pneumoniae. However, it is not known whether these might actually represent false-positives as, according to our analyses, OP swabs showed poorer specificity (90.2\%) compared to NP swabs (96.8\%) (Additional file 1). Furthermore, NP swabs were not assessed by direct fluorescent antigen for specimen adequacy prior to testing. However, excellent specimen adequacy of NP flocked swabs has recently been reported [43]. Nevertheless, due to the lack of diagnostic gold standards, accuracy of such tests is difficult to assess and more research is needed to confirm this finding.

Certain limitations concern data collection and analyses. Firstly, the requirement of rectal temperature $>38.0^{\circ} \mathrm{C}$ may exclude predominantly elderly patients with CAP, who remain afebrile, and hence contribute to explain the low number of nursing home residents in the study. Secondly, some patients who met the inclusion criteria were not enrolled in the study and the complete microbial sampling could not be applied in every patient. We have, however, no reason to suspect these factors to induce systematic selection bias. Thirdly, not all sputum and NP culture samples were taken before administration of antibiotics, which influences the validity of the microbial etiology patterns found and the comparison of diagnostic tests. 
Fourthly, specificity issues have been raised regarding the ply gene used, which has been identified in Streptococcus mitis. However, we used quantitative technique, and any DNA amount of S. mitis would probably have been low, at least in NP samples. Furthermore, we did not include a control group to determine the prevalence of adult pneumococcal nasopharyngeal carriage. The frequency of carriage in Norway hardly differs appreciably from the $4 \%$ reported from Sweden [44]. Also, we used a $C_{\mathrm{q}}$ cut-off value of $10^{5} \mathrm{cfu} / \mathrm{mL}$ to distinguish colonization from true infection [25]. Because we did not include control subjects we were unable to investigate the significance of the proportion of certain viruses, in particular rhinovirus, among patients with CAP. Finally, we included 48 (18\%) patients with immunosuppression (i.e., primary or acquired immunodeficiency, active malignancy, immunosuppressive drugs) that may have an impact on the etiological results. However, this proportion of immunocompromized patients in our study does not exceed $25 \%$ that probably would have hampered comparison of etiological results with other studies from which such patients have been excluded [7]. Moreover, inclusion of these patients may also be a strength of the study as they better reflect the population being referred to this local hospital. These limitations have been considered in the analyses and presentation of results.

\section{Conclusions}

In conclusion, it was possible to establish etiology in 4 out of 5 CAP patients with the aid of PCR, which was particularly useful in diagnosing viral infections. The main pathogens identified were $S$. pneumoniae and viruses, most often influenza viruses and rhinovirus, usually detected with other agents. Viruses were more frequently detected during winter and spring, which was also the time period they occurred most commonly in combination with bacteria. Further research is needed to assess whether OP is superior to NP swabbing for qPCR detection of S. pneumonia in adults with CAP.

\section{Additional file}

Additional file 1: Methods. Details of serological methods. Details of real-time PCR methods and pneumococcal GPCR assay. Determination of the detection range of the pneumococcal GPCR assay and the cut-off quantification cycle $\left(C_{\mathrm{q}}\right)$ value corresponding to $10^{5} \mathrm{cfu} / \mathrm{mL}$. Accuracy of the pneumococcal qPCR assay. Table S1, Table S2, Figure S1, References.

\section{Abbreviations}

CAP: Community-acquired pneumonia; PCR: Polymerase chain reaction; NP: Nasopharynx; OP: Oropharynx; BAL: Bronchoalveolar lavage; CFT: Complement fixation test; ELISA: Enzyme-linked immunosorbent assay; PT-lgG: Serum IgG against pertussis toxin IgG; qPCR: real-time quantitative PCR; Ply: Pneumolysin; RT-PCR: Reverse transcription PCR; $C_{q}$ : quantification cycle; CFU: Colony-forming units; SD: Standard deviation; COPD: Chronic obstructive pulmonary disease; NT: Not tested; ID: Identification; CRF: Case record form; RSV: Respiratory syncytial virus.

\section{Competing interests}

The authors declare that they have no competing interests.

\section{Authors' contributions}

FM, SSF, PA, EH and LH conceived and designed the study. JCH, EH and LH collected and compiled data. JBM reviewed all chest X-rays. JCH, FM, OB, HHS, PAJ and LH carried out the microbiological studies. JCH and TU performed statistical analysis. JCH, FM, PAJ, TU and LH analyzed and interpreted the data. JCH and LH wrote the report. FM, OB, HHS, JBM, PAJ, TU, SSF, PA and EH made substantial intellectual contributions to the work, and commented and revised the report. All authors read and approved the final manuscript.

\section{Acknowledgments}

We thank Dr. Kåre Bø, Dr. Thomas Skrede, Anita Johansen and Britt Hiaasen for collection of patient data; Carina Thilesen, Gro Mannsåker and Eva Eikum for excellent laboratory assistance; and Nihal Perera and Cathrine Brunborg for their contribution to database design and statistical analysis. We also thank Statistics Norway for providing data for this project and Vestre Viken Hospital Trust for financial support.

\section{Author details}

'Department of Internal Medicine, Vestre Viken Hospital Trust, Drammen, Norway. ${ }^{2}$ Department of Medical Microbiology, Vestre Viken Hospital Trust, Drammen, Norway. ${ }^{3}$ Department of Radiology, Vestre Viken Hospital Trust, Drammen, Norway. ${ }^{4}$ Research Institute of Internal Medicine, Oslo University Hospital Rikshospitalet, Oslo, Norway. ${ }^{5}$ Department of Microbiology, Oslo University Hospital Rikshospitalet, Oslo, Norway. ${ }^{6}$ Section of Clinical Immunology and Infectious Diseases, Oslo University Hospital Rikshospitalet, Oslo, Norway. ${ }^{7}$ Institute of Clinical Medicine, Faculty of Medicine, University of Oslo, Oslo, Norway. ${ }^{8}$ K.G. Jebsen Inflammatory Research Center, University of Oslo, Oslo, Norway. ${ }^{9}$ Department of Microbiology, Oslo University Hospital Ullevaal, Oslo, Norway. ${ }^{10}$ Department of Radiology, Hospital of Southern Norway HF, Kristiansand, Norway.

Received: 25 September 2014 Accepted: 4 February 2015

Published online: 15 February 2015

\section{References}

1. Mandell LA, Wunderink RG, Anzueto A, Bartlett JG, Campbell GD, Dean NC, et al. Infectious Diseases Society of America/American Thoracic Society consensus guidelines on the management of community-acquired pneumonia in adults. Clin Infect Dis. 2007:44 Suppl 2:S27-72.

2. Lim WS, Baudouin SV, George RC, Hill AT, Jamieson C, Le Jeune I, et al. BTS guidelines for the management of community acquired pneumonia in adults: update 2009. Thorax. 2009;64 Suppl 3:iii1-55.

3. Spindler C, Stralin K, Eriksson L, Hjerdt-Goscinski G, Holmberg H, Lidman C, et al. Swedish guidelines on the management of community-acquired pneumonia in immunocompetent adults-Swedish Society of Infectious Diseases 2012. Scand J Infect Dis. 2012;44(12):885-902.

4. File TM. Community-acquired pneumonia. Lancet. 2003;362(9400):1991-2001.

5. Ruiz M, Ewig S, Marcos MA, Martinez JA, Arancibia F, Mensa J, et al. Etiology of community-acquired pneumonia: impact of age, comorbidity, and severity. Am J Respir Crit Care Med. 1999;160(2):397-405.

6. Brown JS. Geography and the aetiology of community-acquired pneumonia. Respirology. 2009;14(8):1068-71

7. Woodhead M. Community-acquired pneumonia in Europe: causative pathogens and resistance patterns. Eur Respir J Suppl. 2002;36:20s-7.

8. Bartlett JG. Diagnostic tests for agents of community-acquired pneumonia. Clin Infect Dis. 2011;52 Suppl 4:S296-304.

9. Schreiner $A D$, Digranes $A$. Bacteriology of acute lower respiratory tract infections. J Infect. 1979;1 Suppl 2:23-30.

10. Johansson N, Kalin M, Giske CG, Hedlund J. Quantitative detection of Streptococcus pneumoniae from sputum samples with real-time quantitative polymerase chain reaction for etiologic diagnosis of community-acquired pneumonia. Diagn Microbiol Infect Dis. 2008;60(3):255-61.

11. Johansson N, Kalin M, Tiveljung-Lindell A, Giske CG, Hedlund J. Etiology of community-acquired pneumonia: increased microbiological yield with new diagnostic methods. Clin Infect Dis. 2010;50(2):202-9.

12. Luchsinger V, Ruiz M, Zunino E, Martinez MA, Machado C, Piedra PA, et al. Community-acquired pneumonia in Chile: the clinical relevance in the detection of viruses and atypical bacteria. Thorax. 2013;68(11):1000-6. 
13. Sangil A, Calbo E, Robles A, Benet S, Viladot ME, Pascual V, et al. Aetiology of community-acquired pneumonia among adults in an H1N1 pandemic year: the role of respiratory viruses. Eur J Clin Microbiol Infect Dis. 2012;31(10):2765-72.

14. Huijskens EG, van Erkel AJ, Palmen FM, Buiting AG, Kluytmans JA, Rossen JW. Viral and bacterial aetiology of community-acquired pneumonia in adults. Influenza Other Respi Viruses. 2013;7(4):567-73.

15. van Gageldonk-Lafeber AB, Wever PC, van der Lubben IM, de Jager CP, Meijer A, de Vries MC, et al. The aetiology of community-acquired pneumonia and implications for patient management. Neth J Med. 2013;71(8):418-25.

16. Templeton KE, Scheltinga SA, van den Eeden WC, Graffelman AW, van den Broek PJ, Claas EC. Improved diagnosis of the etiology of community-acquired pneumonia with real-time polymerase chain reaction. Clin Infect Dis. 2005:41(3):345-51.

17. Pavia AT. What is the role of respiratory viruses in community-acquired pneumonia?: What is the best therapy for influenza and other viral causes of community-acquired pneumonia? Infect Dis Clin North Am. 2013;27(1):157-75.

18. File Jr TM. New diagnostic tests for pneumonia: what is their role in clinical practice? Clin Chest Med. 2011;32(3):417-30.

19. Kirkpatrick MB, Bass Jr JB. Quantitative bacterial cultures of bronchoalveolar lavage fluids and protected brush catheter specimens from normal subjects. Am Rev Respir Dis. 1989;139(2):546-8.

20. Bartlett JG, Dowell SF, Mandell LA, File Jr TM, Musher DM, Fine MJ. Practice guidelines for the management of community-acquired pneumonia in adults. Infectious Diseases Society of America. Clin Infect Dis. 2000;31(2):347-82.

21. Greiner O, Day PJ, Bosshard PP, Imeri F, Altwegg M, Nadal D. Quantitative detection of Streptococcus pneumoniae in nasopharyngeal secretions by real-time PCR. J Clin Microbiol. 2001;39(9):3129-34.

22. Andre P, Caro V, Njamkepo E, Wendelboe AM, Van Rie A, Guiso N. Comparison of serological and real-time PCR assays to diagnose Bordetella pertussis infection in 2007. J Clin Microbiol. 2008;46(5):1672-7.

23. Guiso N, Berbers G, Fry NK, He Q, Riffelmann M, Wirsing von Konig CH. What to do and what not to do in serological diagnosis of pertussis: recommendations from EU reference laboratories. Eur J Clin Microbiol Infect Dis. 2011;30(3):307-12.

24. Albrich WC, Madhi SA, Adrian PV, van Niekerk N, Mareletsi T, Cutland C, et al. Use of a rapid test of pneumococcal colonization density to diagnose pneumococcal pneumonia. Clin Infect Dis. 2012;54(5):601-9.

25. Kais M, Spindler C, Kalin M, Ortqvist A, Giske CG. Quantitative detection of Streptococcus pneumoniae, Haemophilus influenzae, and Moraxella catarrhalis in lower respiratory tract samples by real-time PCR. Diagn Microbiol Infect Dis. 2006;55(3):169-78.

26. Principi N, Terranova L, Zampiero A, Manzoni F, Senatore L, Rios WP, et al. Oropharyngeal and nasopharyngeal sampling for the detection of adolescent Streptococcus pneumoniae carriers. J Med Microbiol. 2014;63(Pt 3):393-8.

27. Angeles Marcos M, Camps M, Pumarola T, Antonio Martinez J, Martinez E, Mensa J, et al. The role of viruses in the aetiology of community-acquired pneumonia in adults. Antivir Ther. 2006;11(3):351-9.

28. Jennings LC, Anderson TP, Beynon KA, Chua A, Laing RT, Werno AM, et al. Incidence and characteristics of viral community-acquired pneumonia in adults. Thorax. 2008;63(1):42-8.

29. Lieberman D, Shimoni A, Shemer-Avni Y, Keren-Naos A, Shtainberg R, Lieberman D. Respiratory viruses in adults with community-acquired pneumonia. Chest. 2010;138(4):811-6.

30. Johnstone J, Majumdar SR, Fox JD, Marrie TJ. Viral infection in adults hospitalized with community-acquired pneumonia: prevalence, pathogens, and presentation. Chest. 2008;134(6):1141-8.

31. Charles PG, Whitby M, Fuller AJ, Stirling R, Wright AA, Korman TM, et al. The etiology of community-acquired pneumonia in Australia: why penicillin plus doxycycline or a macrolide is the most appropriate therapy. Clin Infect Dis. 2008:46(10):1513-21.

32. Apisarnthanarak A, Mundy LM. Etiology of community-acquired pneumonia. Clin Chest Med. 2005;26(1):47-55.

33. Gabutti G, Rota MC. Pertussis: a review of disease epidemiology worldwide and in Italy. Int J Environ Res Public Health. 2012:9(12):4626-38.

34. Blystad H, Anestad G, Vestrheim DF, Madsen S, Ronning K. Increased incidence of Mycoplasma pneumoniae infection in Norway 2011. Euro Surveill. 2012;17(5). http://www.eurosurveillance.org/ViewArticle.aspx? Articleld $=20074$
35. Cesario TC. Viruses associated with pneumonia in adults. Clin Infect Dis. 2012;55(1):107-13.

36. Jartti $T$, Jartti L, Ruuskanen $\mathrm{O}$, Soderlund-Venermo M. New respiratory viral infections. Curr Opin Pulm Med. 2012;18(3):271-8.

37. Ruuskanen O, Lahti E, Jennings LC, Murdoch DR. Viral pneumonia. Lancet. 2011;377(9773):1264-75.

38. Ruuskanen $\mathrm{O}$, Jarvinen $\mathrm{A}$. What is the real role of respiratory viruses in severe community-acquired pneumonia? Clin Infect Dis. 2014;59:71-3.

39. Oosterheert JJ, van Loon AM, Schuurman R, Hoepelman Al, Hak E, Thijsen S, et al. Impact of rapid detection of viral and atypical bacterial pathogens by real-time polymerase chain reaction for patients with lower respiratory tract infection. Clin Infect Dis. 2005;41(10):1438-44.

40. Karhu J, Ala-Kokko TI, Vuorinen T, Ohtonen P, Syrjala H. Lower respiratory tract virus findings in mechanically ventilated patients with severe community-acquired pneumonia. Clin Infect Dis. 2014;59:62-70.

41. Lim WS, Macfarlane JT, Boswell TC, Harrison TG, Rose D, Leinonen M, et al. Study of community acquired pneumonia aetiology (SCAPA) in adults admitted to hospital: implications for management guidelines. Thorax. 2001;56(4):296-301.

42. Hernes SS, Quarsten $H$, Hagen E, Lyngroth AL, Pripp AH, Bjorvatn B, et al. Swabbing for respiratory viral infections in older patients: a comparison of rayon and nylon flocked swabs. Eur J Clin Microbiol Infect Dis. 2011;30(2):159-65.

43. Pollock NR, Duong S, Cheng A, Han LL, Smole S, Kirby JE. Ruling out novel H1N1 influenza virus infection with direct fluorescent antigen testing. Clin Infect Dis. 2009:49(6):e66-8.

44. Stralin K, Olcen P, Tornqvist E, Holmberg H. Definite, probable, and possible bacterial aetiologies of community-acquired pneumonia at different CRB-65 scores. Scand J Infect Dis. 2010;42(6-7):426-34.

\section{Submit your next manuscript to BioMed Central and take full advantage of:}

- Convenient online submission

- Thorough peer review

- No space constraints or color figure charges

- Immediate publication on acceptance

- Inclusion in PubMed, CAS, Scopus and Google Scholar

- Research which is freely available for redistribution 